\title{
A new method for correcting temperature log profiles in low-enthalpy plays
}

\author{
Sandra Schumacher ${ }^{1 *}$ (1) and Inga Moeck²
}

\author{
*Correspondence: \\ sandra.schumacher@bgr.de \\ ${ }^{1}$ Federal Institute \\ for Geosciences and Natural \\ Resources, Stilleweg 2, \\ Hannover 30655, Germany \\ Full list of author information \\ is available at the end of the \\ article
}

\begin{abstract}
Temperature logs recorded shortly after drilling operations can be the only temperature information from deep wells. However, these measurements are still influenced by the thermal disturbance caused by drilling and therefore do not represent true rock temperatures. The magnitude of the thermal disturbance is dependent on many factors such as drilling time, logging procedure or mud temperature. However, often old well reports lack this crucial information so that conventional corrections on temperature logs cannot be performed. This impedes the re-evaluation of well data for new exploration purposes, e.g. for geothermal resources. This study presents a new method to correct log temperatures in low-enthalpy play types which only requires a knowledge of the final depth of the well as an input parameter. The method was developed and verified using existing well data from an intracratonic sedimentary basin, the eastern part of the North German Basin. It can be transferred to other basins with little or no adjustment.
\end{abstract}

Keywords: Temperature correction, Depth-dependent, North German Basin, Sedimentary basin

\section{Introduction}

A knowledge of the correct subsurface temperature regime in a well is not only important for the hydrocarbon industry, but also for geothermal purposes (e.g. Ganz 2015; Schumacher et al. 2020), as well as for modelling of the thermal state in a particular region (e.g. Norden et al. 2012) or of the crust (e.g. Bonté et al. 2012; Agemar et al. 2012) or even the entire lithosphere (e.g. Bayer et al. 1997; Norden et al. 2008; Freymark et al. 2017; Przybycin et al. 2017).

Temperature measurements in boreholes have been carried out for more than 100 years. However, researchers have struggled to obtain accurate formation temperature measurements which can be used to understand the thermal regime in the subsurface (e.g. Jessop 1990).

\section{Thermal disturbance}

Temperature data can be recorded directly after the end of drilling operations or after a gap of some time. During drilling, mud is circulated in the borehole to cool the drill bit and remove cuttings. The temperature within the borehole therefore deviates from the source, provide a link to the Creative Commons licence, and indicate if changes were made. The images or other third party material in this article are included in the article's Creative Commons licence, unless indicated otherwise in a credit line to the material. If material is not included in the article's Creative Commons licence and your intended use is not permitted by statutory regulation or exceeds the permitted use, you will need to obtain permission directly from the copyright holder. To view a copy of this licence, visit http://creativeco mmons.org/licenses/by/4.0/. 
the formation temperature due both to frictional heating caused by the drill bit and also due to the temperature differences between the rock and the drilling mud (Jessop 1990). This effect increases with the increasing duration of the drilling operation. Moreover, the thermal disturbance caused by the circulating drilling mud is not equally distributed over the length of the borehole. For deep boreholes (> $1000 \mathrm{~m}$ ), the lower part of the borehole is cooled down by the drilling mud. As a consequence, heat is exchanged between the formation and the drilling mud. On its way up from the bottom to the surface, the heated up drilling mud then loses some of its heat to the cold upper parts of the well and in turn heats them up (e.g. Jaeger 1961; Dowdle and Cobb 1975). Thus, two opposing trends (cooling of the lower parts and heating up of the upper parts) are manifest within a single borehole and have to be considered if temperature logs are to be corrected.

Different types of temperature measurements, however, are affected by the described processes to different degrees. Thus, bottom-hole temperatures (BHTs), which usually are single temperature measurements made at the bottom of the borehole shortly after the end of mud circulation, are prone to large errors (e.g. Bullard 1947; Dowdle and Cobb 1975). By contrast, temperature logs, which are recorded over a significant part of the borehole length and often even continuously from the surface to the total depth, may provide a more accurate representation of the thermal field, especially if they are recorded some time after the end of mud circulation. In addition, logs may capture variations in the geothermal gradient, which single point measurements cannot deliver. Finally, production tests or drill-stem tests can provide a reliable source of subsurface temperature information as the temperature of water produced from a given formation is assumed to correspond closely the temperature of the rock (e.g. Perrier and RaigaClemenceau 1984; Hermanrud et al. 1990). However, the reliability of the temperature information can be severely compromised if the drill-stem test or the production test is preceded by extensive drilling operations or an injection test.

Even though different types of temperature measurements have smaller or larger inherent errors, they are all affected by the same problem, namely: if insufficient time has elapsed since the end of drilling, the measured data will be subjected to the thermal disturbance caused by the drilling process (e.g. Bullard 1947; Lachenbruch and Brewer 1959; Perrier and Raiga-Clemenceau 1984; Zschocke 2005).

\section{Existing correction methods for log temperatures}

The importance of correcting log temperatures is shown by the extensive research which has been carried out in this field over the past half-century or more. Thus, Bullard (1947) suggested that, at the end of mud circulation, it was necessary to wait for a length of time equal to 10-20 times the duration of drilling operations to obtain reliable formation temperature measurements. Lachenbruch and Brewer (1959) reported values of eight times the duration of the drilling operations until the effect of fluid circulation on the formation temperature was less than $0.01{ }^{\circ} \mathrm{C}$. Repeated measurements after the end of drilling show that measured temperatures approach formation temperature asymptotically and can therefore be used to determine it. However, such repeated measurements are seldom available. Thus, the correction method suggested by Bullard (1947) cannot often be employed and other correction methods have been developed as a result. 
Most of the correction methods developed for temperature recordings were devised for BHT measurements and cannot be transferred to measurements of the temperature profile indiscriminately. An example is the correction method proposed by Kutasov and Eppelbaum (2010), which is only valid for BHTs as it depends on the assumption that the thermal disturbance close to the well bottom is short-lived. A variety of other correction methods rely on the Horner method (Horner 1951), which requires multiple measurements to be made at different times after the end of mud circulation (e.g. Dowdle and Cobb 1975; Fertl et al. 1986; Cao et al. 1988). A correction method which combines the Horner method with estimates of the radial heat flow and thus does not require multiple measurements at different times after the end of mud circulation was proposed by Zschocke (2005). However, to arrive at good estimates of the equilibrium temperature this method depends on information about the well's radius, the thermal diffusivity of the rock, the time of exposure of the formation to the circulating mud and the shut-in time.

Other authors correlate the necessary corrections with depth. Harrison et al. (1982) established a depth-dependent correction curve for BHTs of wells with depths between 3,000 and 10,000 ft in Oklahoma based on the differences between BHT values and reliable temperature measurements in the same area.

Another approach to temperature correction is based on the time since the end of mud circulation. Examples of this approach include Waples and Ramly (2001), who used drill-stem test data from the Malay Basin to develop a statistical correction method based on the time since the end of mud circulation and thus indirectly on depth. Similarly, Zare-Reisabadi et al. (2015) relied directly on information about depth and time since the end of mud circulation to develop a correction method for wells in the Persian Gulf.

In order to obtain better input heat flow data, Norden et al. (2008) developed a correction method for thermal gradients using a subset of temperature logs from the North German Basin discussed in this study. For five wells, the authors used the corrected temperatures at the lowermost log depth from Förster (2001) and the crossover point defined in this study (see section "Cross-over point") to obtain corrected log values for the complete length of the log profile. For these wells, mean temperature gradients between the surface and the cross-over point as well as between crossover point and corrected bottom log temperature were determined. However, no corrected log temperatures were calculated.

In addition to the afore-mentioned correction methods, which rely on analytical approaches, numerical modelling can be used to infer the correct formation temperature from temperature logs. However, such numerical models (e.g. EspinosaParedes and Garcia-Gutierrez 2003; Espinosa-Paredes and Espinosa-Martínez 2009; Yang et al. 2015; Wang et al. 2019) require detailed information about the well (e.g. well geometry) and its drilling process (e.g. mud flow rate, mud properties) to provide good results. However, especially in high-enthalpy regions, where the difference between measured temperature logs and true formation temperature can be very high due to occurring convection, numerical modelling which takes convection into account can deliver better corrected temperatures than analytical models (Wang et al. 2019). 


\section{Available temperature data}

This study is based on temperature logs from wells in the eastern part of the North German Basin, publicly available from the Geophysics Information System of the Leibniz Institute for Applied Geophysics (Kühne et al. 2003). This information system provides information on a range of geophysical measurements made in Germany including temperature data for more than 11,000 boreholes in Germany. The majority of latter data consist of bottom-hole temperatures, which have been corrected according to the methods proposed by Schulz et al. (1992) based on a Horner-type analysis (Horner 1951) or a line-source model (Bullard 1947). In addition to BHT values, temperature logs and temperature data from production tests are also available.

The data are classified according to their reliability, i.e. their correspondence with true formation temperatures. BHTs are classed in the lowest category of reliability because, even after correction and sometimes multiple measurements for a single depth, they may show major deviations from the true temperature (e.g. Hermanrud et al. 1990; Förster 2001).

Log readings are subdivided into two classes in the Geophysical Information System. The first class consists of logs which were recorded long enough after the end of mud circulation that they can be thought of as undisturbed and to represent (nearly) true formation temperatures.

The second class consists of logs for which the time since the end of circulation was not large enough to provide equilibrated temperatures within the well; these logs are referred to as "disturbed". However, in most of the cases, the time between end of mud circulation and the recording of the log is not known.

Temperature data from production tests are considered to provide the most accurate information on true formation temperatures as, in general, these tests were conducted until stable conditions at the wellhead were achieved. Nevertheless, the data are often not consistent within a single well; in numerous cases, temperatures from production tests are found to be lower than those recorded by disturbed logs. In these cases and where no information about the well's operational history is available, it is probable either that the production test was preceded by an injection test or that no stable flow rate could be achieved. Therefore, such a test shows unrealistically low temperatures. Such temperatures from a production test which deviates substantially from other temperature measurement within a well are considered to be untrustworthy and are stored separately within the Geophysics Information System.

\section{Geothermal play type}

The analysed well data are from the eastern part of the North German Basin (NGB). The NGB represents an intracratonic sedimentary basin where conductive heat transport dominates this geologic system (Moeck 2014). The basin is part of the Central European Basin System (Feldrappe et al. 2007) and contains a Permian to Paleogene volcano-sedimentary fill up to $12 \mathrm{~km}$ thick (Fig. 1). Variable sediment thicknesses are a consequence of the basin evolution with different subsidence and uplifting phases, disturbed by halokinesis of Upper Permian salt rock (Hansen et al. 2007). The Upper Permian salt rock layer are relevant for the basin wide heat transport mechanisms. 3D finite element simulations have shown that 


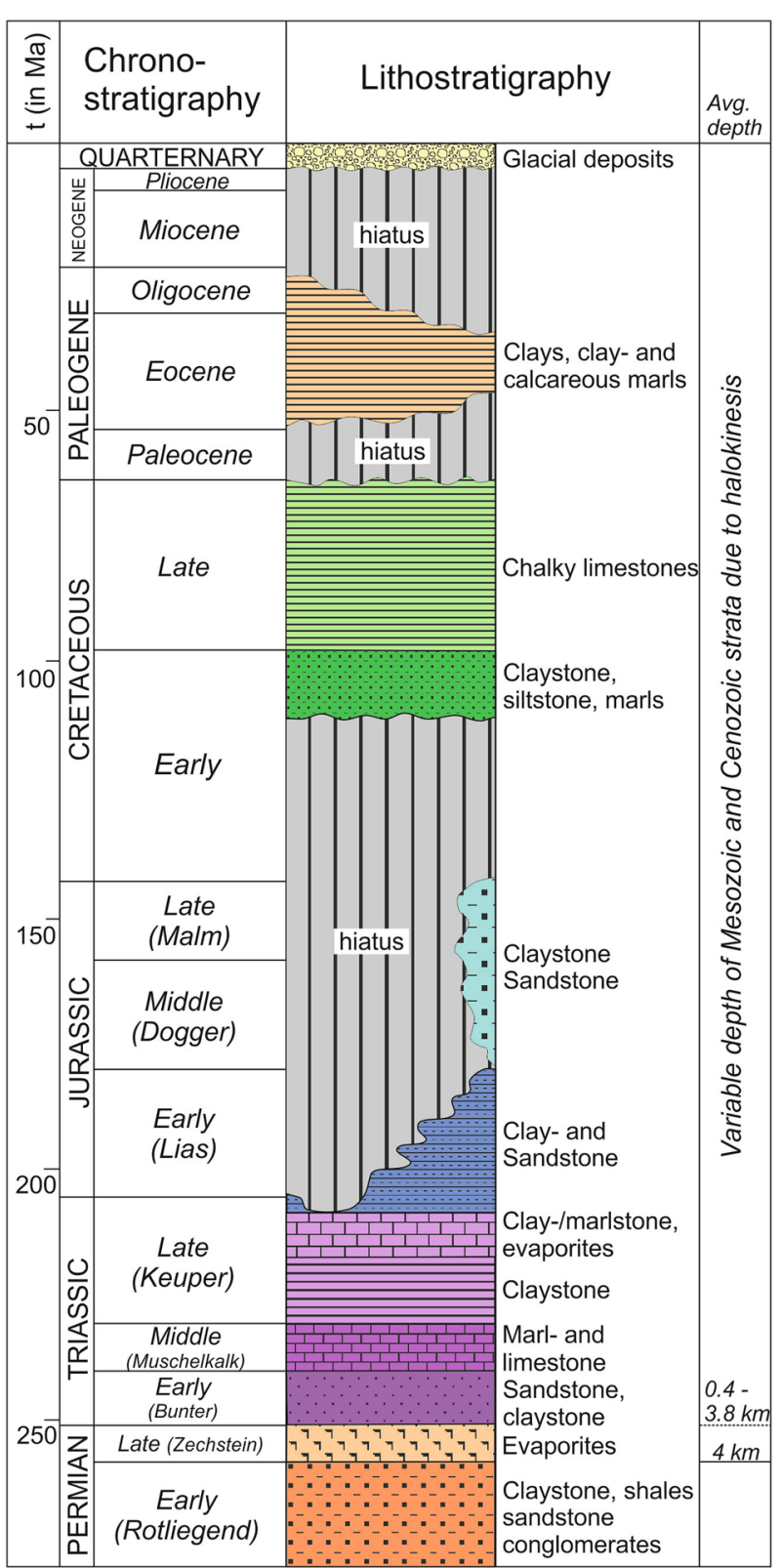

Fig. 1 Stratigraphy of the North German Basin

advective or convective heat transport can have an important effect on the heat transfer in suprasalt successions in the vicinity of salt ridges or diapirs (Cherubini et al. 2014). Also large fault zones can have a similar effect, while below the salt successions conduction is the dominating heat transport (Cherubini et al. 2014; Scheck-Wenderoth et al. 2014). In the absence of large fault zones and halokinetic structures, conduction is the dominant mechanism in the NGB, controlled by geologic-petrophysical factors such as thermal conductivity, sedimentary thickness or lower crust properties (Scheck-Wenderoth et al. 2014). Since the analysed well data are far afield from regional fault zones or halokinetic 
structures, conduction is suggested as dominating heat transport, representative for other low-enthalpy sedimentary basins worldwide (Majorowicz et al. 2014; Moeck 2014).

The eastern part of the NGB covers the territory of the former German Democratic Republic (GDR). From 1962 to 1990 more than 1,000 deep reconnaissance and exploration wells were drilled here to search for energy resources such as natural gas, oil or geothermal reservoirs. Temperature logs from some of these wells were used to develop the new method for temperature log correction detailed in this study. One of the deepest boreholes is the well Mirow 1/74 drilled from 1974 to 1977 to a depth of 8,008 m (Hoth et al. 1993), being the deepest well on the European continent until the KTB was drilled in the 1990s.

\section{Methods}

The only data consistently available for all temperature logs in the analysed area (the eastern part of the North German Basin) are the temperature measurements themselves and the depths at which they were recorded. Other data, such as the time interval between end of mud circulation and temperature measurements are only sparsely represented in the Geophysical Information System. Therefore, correction methods which are based on information such as the time since the end of mud circulation cannot be employed. In this study, we present three newly developed correction methods (A, B and C: see below) based on basic, commonly available information. The performance of these methods was tested against production test data for the wells analysed to appraise their validity. In total, temperature measurements as well as production test data were available for 25 wells in the eastern part of the North German Basin (Fig. 2).

\section{Cross-over point}

Förster (2001) analysed log temperatures of 13 wells in the eastern part of the NGB, for which temperature data were recorded at different times after the end of mud circulation. The analyses showed that there exists a depth-point in each of these wells at which the thermal disturbance due to mud circulation is zero. As the top of a well is heated by the mud circulation and the bottom is cooled, such a point has to exist for each well. The location of this so-called cross-over point was empirically determined as:

$$
z_{C P}=a \cdot z_{f}+b,
$$

where $z_{C P}$ is the depth of the cross-over point [m], parameter $a=0.39$ is an empirically derived fitting parameter, parameter $b=267 \mathrm{~m}$ and $z_{f}$ is the final depth of the borehole [m] (Förster 2001).

\section{Thermal disturbance}

In order to determine the magnitude of the thermal disturbance for each log, the surface temperature of the log is compared to the true surface temperature and the resulting temperature difference is taken as a measure for the thermal disturbance:

$$
\Delta T=T_{0}-T_{s},
$$

with $\Delta T$ being the temperature difference $[\mathrm{K}]$ between the surface temperature taken from the temperature $\log , T_{0}\left[{ }^{\circ} \mathrm{C}\right]$, and the true surface temperature $T_{s}\left[{ }^{\circ} \mathrm{C}\right]$ recorded at a depth of about $13 \mathrm{~m}$ depth. The true surface temperature was measured at this depth 


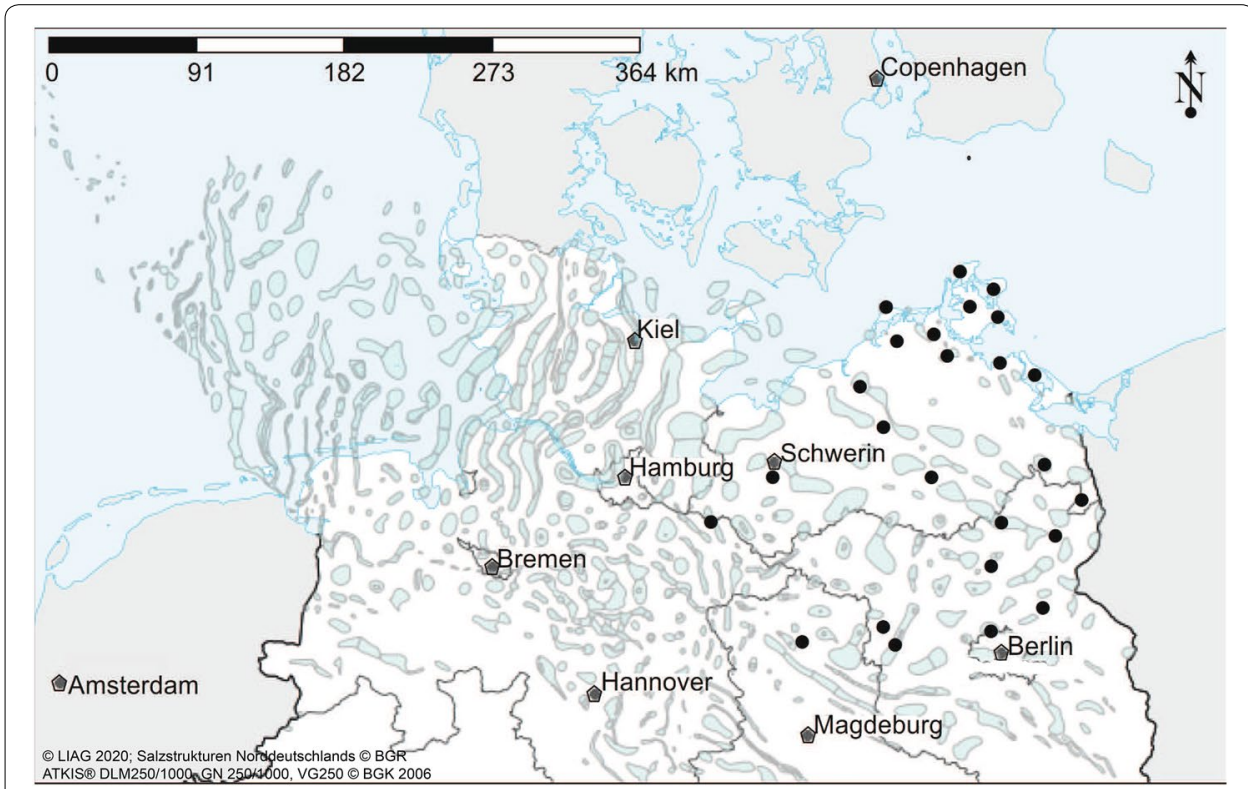

Fig. 2 Locations of the analysed wells. Black points: locations of the wells used for this study; grey pentagons: large cities; blue-green areas: halokinetic structures

to take account of seasonal temperature and was derived from data from the German Meteorological Survey (Agemar et al. 2012).

The surface temperature from the temperature log is in most cases not readily available, but had to be extrapolated from log measurements in deeper parts of the borehole. An underlying assumption for this linear extrapolation is that the thermal conductivity does not vary significantly between the surface and the depths at which the temperature was measured.

The depth of the uppermost log measurements varies between 50 and $1000 \mathrm{~m}$, with the majority of measurements made at a depth of $100 \mathrm{~m}$ to $200 \mathrm{~m}$ (Fig. 3).

In order to analyse the uncertainties introduced by extrapolating log measurements at a given depth to the surface, additional extrapolations were carried out for existing measurements. For this, the uppermost log readings were ignored and linear extrapolations were performed to the depths of these uppermost log measurements.

The linear extrapolations used log measurements starting at a depth of $200 \mathrm{~m}$ or $500 \mathrm{~m}$ and encompass temperature measurements over an interval of 200 to $400 \mathrm{~m}$ below the starting depth. The interval chosen depends on the thermal gradient. A relatively large interval (e.g. $400 \mathrm{~m}$ ) is in general preferable for the extrapolation because it contains more temperature values; however, variations in the thermal gradient over this interval result in a reduction of the correlation coefficient for the linear function used for the extrapolation. Thus, the interval used for the extrapolation is chosen so that the correlation coefficient is as large as possible. 


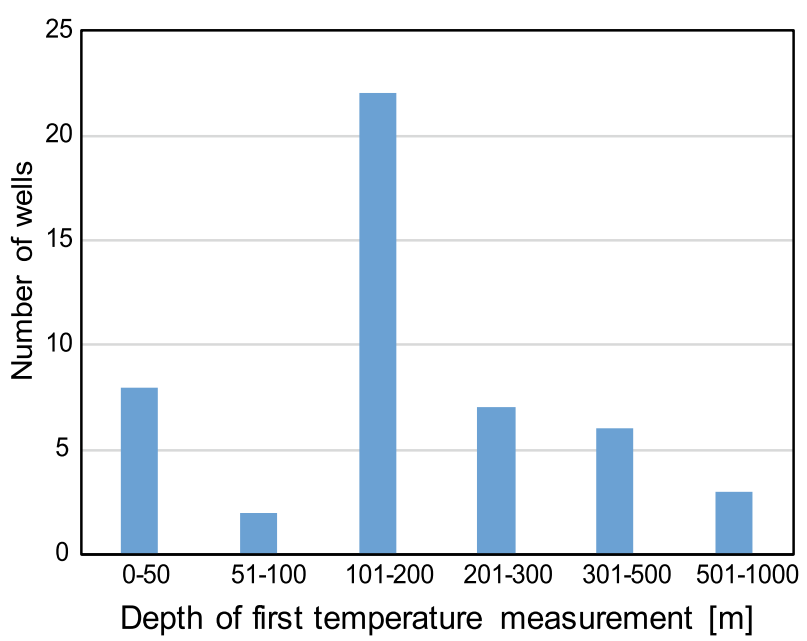

Fig. 3 Depth of first temperature measurement. The number of wells for which the first temperature measurement was made at a given depth

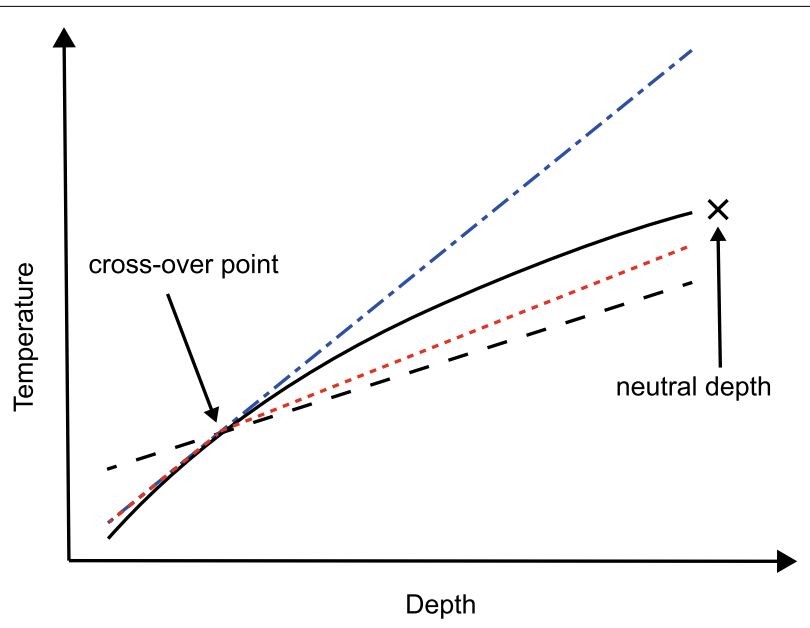

Fig. 4 Sketch of the effects of the different correction methods on the temperature data. Black dashed line: original temperature log; blue dash-dotted line: method A; black solid line: method B; red dotted line: method C

\section{Method A}

The first correction equation developed is based on a rotation of the disturbed log around the cross-over point (Fig. 4) defined by Eq. 1 so that the thermal disturbance at the surface equals zero:

$$
T_{c 1}(z)=T_{\log }-\left(\Delta T-\frac{\Delta T \cdot z}{z_{C P}}\right)
$$

where $T_{c 1}(z)$ is the corrected temperature value $\left[{ }^{\circ} \mathrm{C}\right]$ at a given depth $z[\mathrm{~m}], T_{\log }$ the original temperature log value at this depth and $z_{C P}$ is the depth of the cross-over point. The correction method based on this equation is referred to hereafter as method $\mathrm{A}$. 


\section{Method B}

For a second correction equation, the same rotation of the disturbed log around the cross-over point as in Eq. 3 is used. However, it is also assumed that the thermal disturbance at the time of measurement is at a maximum at the surface, while it should be zero some metres below final well depth. This first-order approximation adds another factor to Eq. 3, which leads to following equation:

$$
T_{c 2}(z)=T_{\log }-\left(\Delta T-\frac{\Delta T \cdot z}{z_{C P}}\right) \cdot\left(1-\frac{z}{z_{f}+c}\right),
$$

where $T_{c 2}(z)$ is the corrected temperature value $\left[{ }^{\circ} \mathrm{C}\right]$ in a given depth $z[\mathrm{~m}]$ and $z_{f}$ is the final well depth $[\mathrm{m}]$. Parameter $c[\mathrm{~m}]$ describes the additional depth in metres, below the final well depth, at which the thermal disturbance is zero. This depth is termed the "neutral depth" and as a first assumption set to $50 \mathrm{~m}$ below final depth. The correction method based on Equation 4 is referred to hereafter as method B.

Method B is based on method A, but contains an additional term. This additional term is assigned a value of 1 for the thermal disturbance at the surface and a value of 0 for the thermal disturbance in the neutral depth. The underlying assumption is that the drilling process acted $100 \%$ of the total drilling time on the temperatures at the surface, while it had no time to act on the temperatures at the neutral depth. Due to a lack of information regarding the actual progress of drilling with time, a linear interpolation between the surface and the neutral depth is performed.

While the cross-over point is in general located within the upper third of the well (depending on its final depth), the neutral depth is always below the final well depth (Fig. 4).

\section{Method C}

In addition to Eqs. 3 and 4, a third correction equation is analysed, which is based on the published corrected BHTs by Förster (2001). Here, the temperature difference $\left(\Delta T_{2}\right)$ between the lowermost log measurement and the corrected value by Förster (2001) for this depth has been used to correct the log temperatures below the cross-over point. For the upper part of the well, the same correction as for method A applies:

$$
T_{c 3}(z)= \begin{cases}T_{\log }-\left(\Delta T-\frac{\Delta T \cdot z}{z_{C P}}\right) & \text { for } \mathrm{z}<\mathrm{z}_{\mathrm{CP}} \\ T_{\log }+\Delta T_{2} \cdot\left(\frac{z-z_{C P}}{z_{\log }-z_{C P}}\right) & \text { for } \mathrm{z} \geq \mathrm{z}_{\mathrm{CP}}\end{cases}
$$

where $T_{c 3}(z)$ is the corrected temperature $\left[{ }^{\circ} \mathrm{C}\right]$ in a given depth $z$ and $z_{\log }$ the depth of the lowermost log measurement $[\mathrm{m}]$. The correction method based on this equation is referred to hereafter as method $\mathrm{C}$.

\section{Interpolation or extrapolation to production test depth}

For the wells analysed, no log temperatures were recorded in the depths for which production test temperatures are available for comparison; thus temperatures for production test depths were interpolated from at least the four nearest log measurements. 
Which and how many measurements were used for the interpolation depended on the lithology encountered by the well. If the production test is located close to a significant change in lithology and thereby an obvious change in the thermal gradient, only log values within the same lithology as the production test were used.

In several cases, the production test depths were greater than the final depth of the log measurements. Here, the temperature for the depth in question was linearly extrapolated from the last log temperatures.

The interpolated or extrapolated temperatures were subsequently corrected using the methods $\mathrm{A}$ to $\mathrm{C}$ described above.

\section{Results}

\section{Extrapolation}

As a direct evaluation of the linear extrapolation used for the surface temperatures is not possible in the wells analysed due to a lack of data, extrapolations to a depth close to the surface were performed using the existing data set. The uppermost log temperature was ignored and log temperatures starting at depths of either $200 \mathrm{~m}$ or $500 \mathrm{~m}$ depth were extrapolated to the depth of the uppermost log temperature. A comparison between actual measurements and extrapolated temperatures is shown in Fig. 5. No significant difference between data sets starting in a depth of $200 \mathrm{~m}$ or $500 \mathrm{~m}$ can be observed.

To quantify the error associated with the extrapolation, the normalised temperature difference (i.e. the total temperature difference divided by the depth difference) between measured and extrapolated log measurement was plotted versus the depth difference between the measured value and the topmost value used for the extrapolation (Fig. 6). This plot shows that there is a systematic overestimation of the temperature. Interestingly, a trend towards a decreasing temperature error per metre can be seen for greater depth differences.

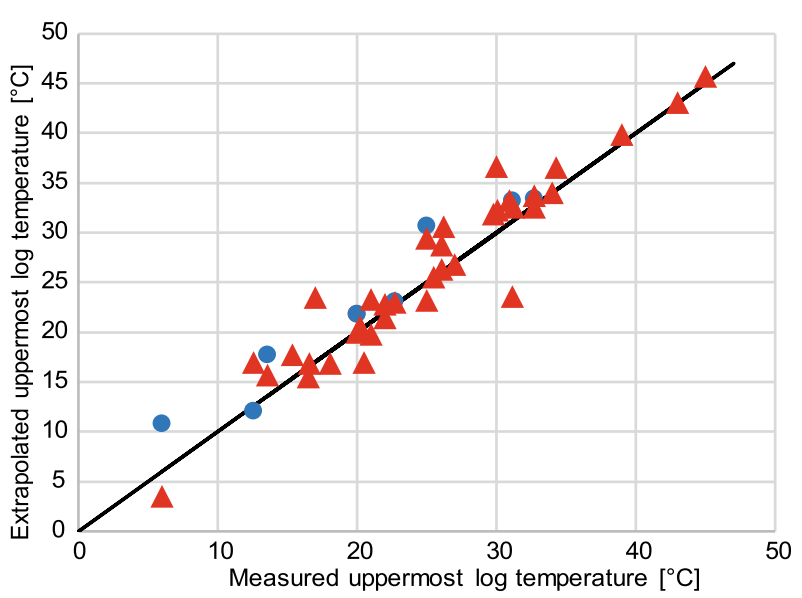

Fig. 5 Measured versus extrapolated uppermost log measurements. The black line indicates the perfect fit. Blue dots: extrapolations using values starting in a depth of $200 \mathrm{~m}$; red triangles: extrapolations using values starting in a depth of $500 \mathrm{~m}$ 


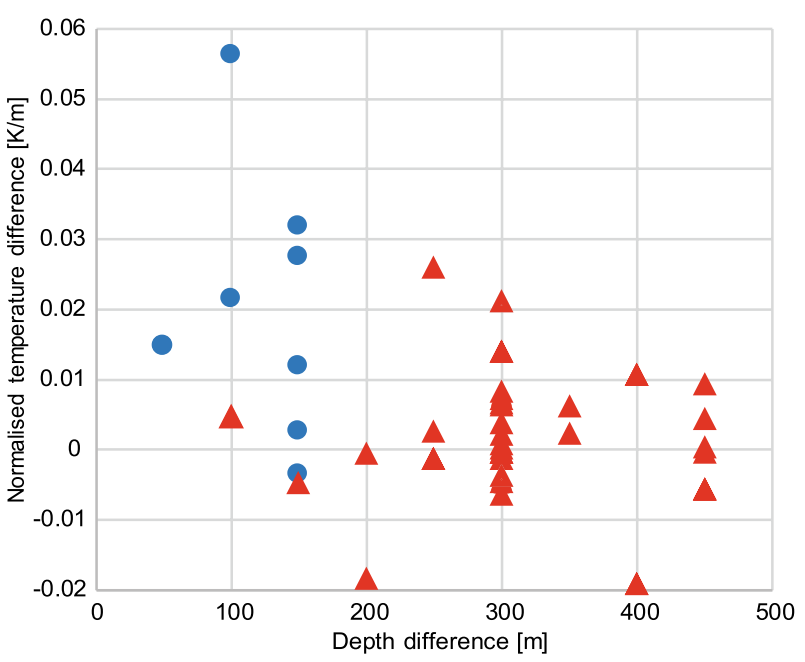

Fig. 6 Temperature difference between measured and extrapolated log temperatures. Normalised temperature difference between measured and extrapolated log temperatures versus the depth difference between the measured value and the topmost value used for the extrapolation. Blue dots: extrapolations using values from a depth of $200 \mathrm{~m}$ downwards; red triangles: extrapolations using only values from a depth of $500 \mathrm{~m}$ downwards

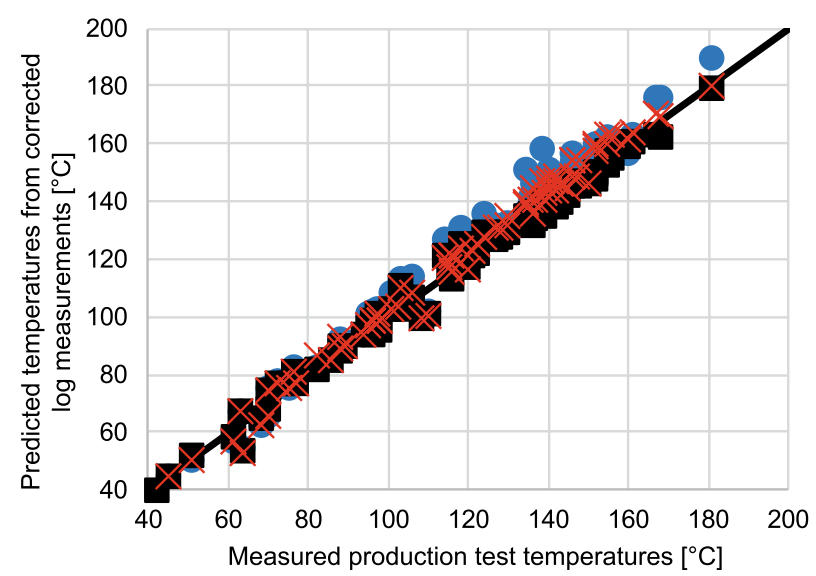

Fig. 7 Predicted temperatures from corrected log measurements versus temperatures measured during production tests. The black line indicates perfect correlation. Blue dots: method $A_{;}$black squares: method $B$; red crosses: method C

\section{Production tests}

The only way to analyse the validity of the proposed correction equations is to compare them with temperature measurements from production tests, which are believed to give a good representation of the true formation temperature. For 25 wells in the eastern part of the North German Basin both disturbed temperature logs and temperature measurements from production tests were available; however, the depth of the log measurement did not coincide with the depth of the production test measurement in any of them. Therefore, theoretical temperatures were calculated from the log measurements for the depths of the production tests. Thus, linear interpolation or extrapolation was necessary 


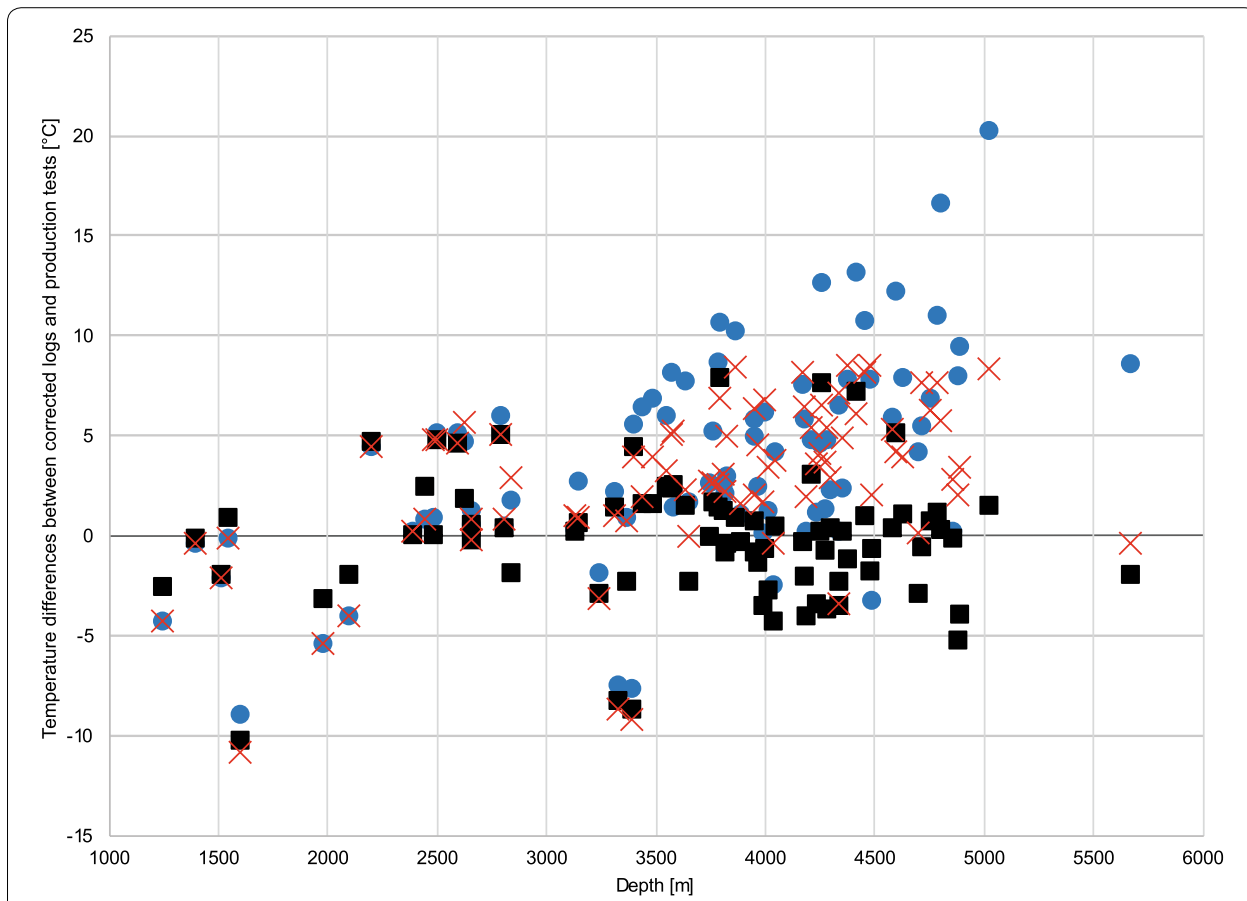

Fig. 8 Differences between measured production test temperatures and predicted temperatures from corrected logs. Blue dots: method A; black squares: method B; red crosses: method C

Table 1 Temperature differences to production test data for the three correction methods analysed. The average error as well as the standard deviation $(\sigma)$ are shown. To highlight potential shortcomings of each method, separate statistics are exhibited for data which were interpolated from corrected logs and those which had to be extrapolated as the production test was in a larger depth than the final log measurement

\begin{tabular}{|c|c|c|c|c|c|c|}
\hline \multirow[t]{2}{*}{ Correction method } & \multicolumn{2}{|c|}{ All production tests } & \multicolumn{2}{|c|}{ Interpolated values only } & \multicolumn{2}{|c|}{$\begin{array}{l}\text { Extrapolated values } \\
\text { only }\end{array}$} \\
\hline & $\begin{array}{l}\text { Average error } \\
{[\mathrm{K}]}\end{array}$ & $\sigma[\mathrm{K}]$ & $\begin{array}{l}\text { Average error } \\
{[\mathrm{K}]}\end{array}$ & $\sigma[\mathrm{K}]$ & $\begin{array}{l}\text { Average error } \\
{[\mathrm{K}]}\end{array}$ & $\sigma[\mathrm{K}]$ \\
\hline A (Eq. 3) & 4.3 & 5.3 & 4.0 & 5.5 & 4.7 & 4.0 \\
\hline B (Eq. 4) & 0.0 & 3.2 & 0.5 & 3.3 & -1.6 & 2.4 \\
\hline C (Eq. 5) & 3.1 & 3.7 & 2.7 & 3.2 & 4.2 & 4.7 \\
\hline
\end{tabular}

to obtain temperature value predictions for the production test depths using the correction equations. The results of these calculations are shown in Fig. 7.

Differences in temperatures between production test measurements and predictions from the corrected logs are rarely larger than $10 \mathrm{~K}$. As a general trend, it can be observed that predicted temperatures from corrected logs using either Eq. 3 (i.e. a simple rotation around the cross-over point) or Eq. 5 (i.e. fitting the log to corrected BHTs) often overestimate the true formation temperature. Equation 4 on the other hand shows a tendency to underestimate temperatures, especially for higher values.

These findings become even more apparent in Fig. 8, which shows the difference in production test data and predictions from corrected logs versus depth. For depths 
below the cross-over point (whose average value for the analysed wells is about 2100 $\mathrm{m}$ ), the temperature differences are predominantly positive for Eq. 3 and 5, but are more equally balanced for Eq. 4. Statistical data for each correction method are presented in Table 1. For each method, the differences between all production test measurements and predictions from corrected logs were analysed for all 25 wells. The average error as well as the standard deviation were computed. Additionally, to examine if there are significant differences in data quality between interpolated and extrapolated corrected log temperatures, both categories were explored separately. Only for method $C$, the extrapolated values are slightly worse than the interpolated values.

Even though the average errors are comparatively small for all three correction methods, the standard deviations are large. Moreover, significant differences between the correction methods can be observed.

\section{Sensitivity analysis}

The sensitivity of the methods to key parameters in their underlying equations was tested.

As all methods are based on Eq. 1, which features two empirically derived parameters $(a$ and $b)$, the influence of variations in these parameters on the average errors and standard deviations of the three correction methods was analysed (Fig. 9). Parameters $a$ and $b$ have only been determined for the North German Basin and their possible range of values in other sedimentary basins is not clear. Thus, both parameters were varied in a range of $\pm 50 \%$ of their values in the North German Basin. Figure 9 shows the sensitivity of the three correction methods to variations in the parameters $a$ and $b$.

Changes to parameter $a$ will have a significantly higher impact on the average errors of all three methods than changes to parameter $b$ (Table 2). For the same variation between $50 \%$ and $150 \%$ of the values of $a$ and $b$ proposed by Förster (2001), the average error changes at least nine times as much for $a$ than for $b$. Moreover, method A is affected most strongly by parameter changes, while changes in either parameter will have a relatively slight impact on the results of methods $B$ and $C$.

The standard deviations of method $B$ and $C$ remain nearly constant with parameter variations (especially for $b$ ), while that of method A shows greater sensitivity. Thus, the standard deviation of method A is the highest in nearly all cases, while that of method B is the lowest for nearly all variations considered (Fig. 9). Moreover, only method B exhibits average errors of zero or close to zero for a large spectrum of parameter variations.

For method B not only the parameters of Eq. 1 are relevant, but also parameter $c$ in Eq. 4, which takes account of the neutral depth. The results of variations of parameter $c$ are shown in Fig. 10.

The average error of method B is only slightly influenced by the choice of the value of $c$ and the error is zero for a value of $71.6 \mathrm{~m}$. The standard deviation varies even less than the average error and remains nearly constant with $3.2 \mathrm{~K}$. Thus, it is not shown in Fig. 10.

\section{Discussion}

\section{Log extrapolation}

The determination of the thermal disturbance at the surface is as a proxy for the unknown time since the end of mud circulation in a borehole. The larger the difference 

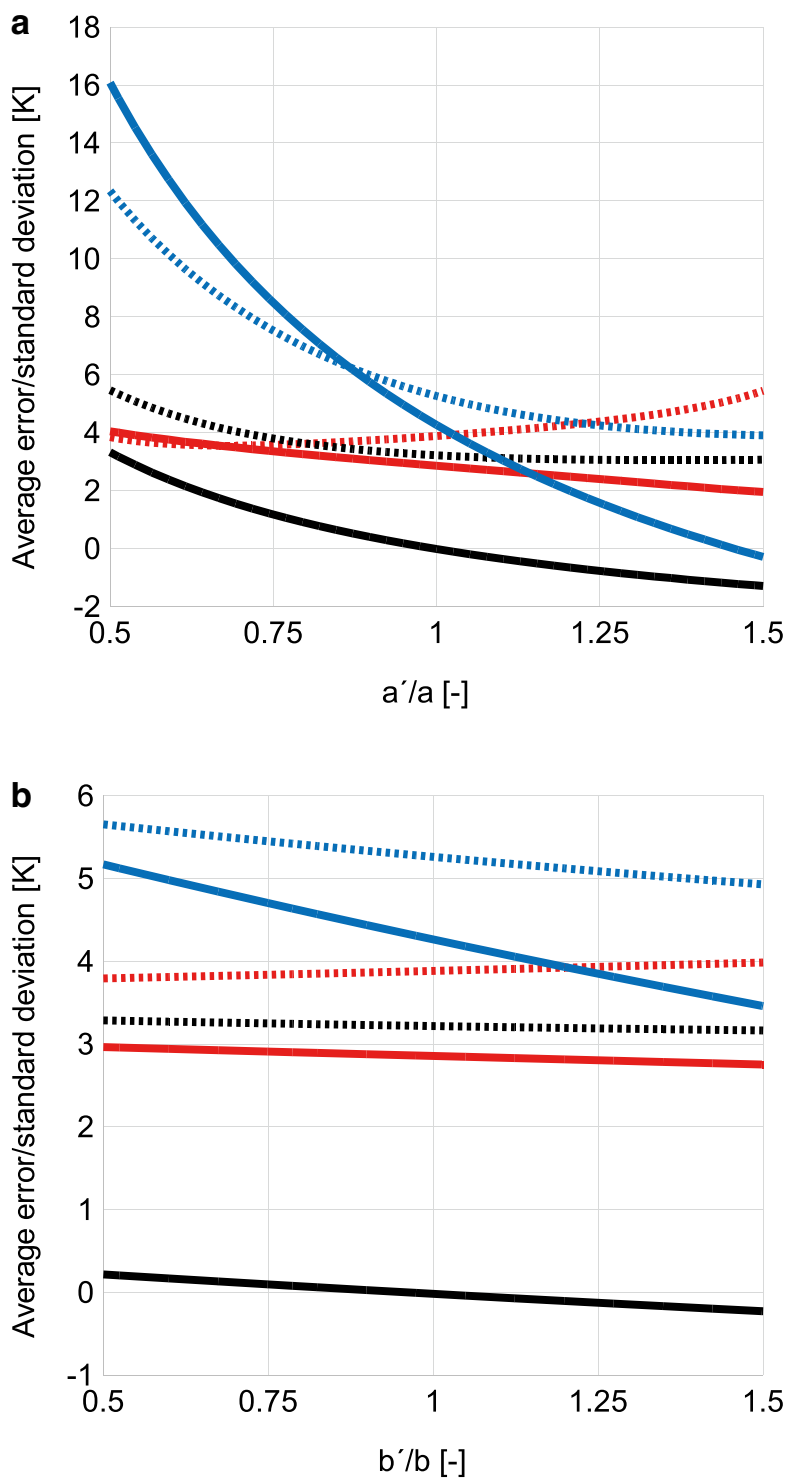

Fig. 9 Average errors and standard deviations. Average error and standard deviation for variations of $\mathbf{a}$ parameter $a$ and $\mathbf{b}$ parameter $b$. Given are normalised parameter values with $a^{\prime}$ and $b^{\prime}$ denoting the parameter variations and $a$ and $b$ the original values according to Eq. 1. Blue lines: results for method $A$; black lines: results for method B; red lines: results for method C. Solid lines: average errors; dashed lines: standard deviations

Table 2 Differences in average error and standard deviation due to variations in parameters $a$ and $b$.

\begin{tabular}{|c|c|c|c|c|c|c|}
\hline \multirow[t]{2}{*}{ Parameter } & \multicolumn{2}{|l|}{ Method A } & \multicolumn{2}{|l|}{ Method B } & \multicolumn{2}{|l|}{ Method C } \\
\hline & $\begin{array}{l}\Delta \text { average error } \\
{[\mathrm{K}]}\end{array}$ & $\Delta \sigma[\mathrm{K}]$ & $\begin{array}{l}\Delta \text { average error } \\
{[\mathrm{K}]}\end{array}$ & $\Delta \sigma[\mathrm{K}]$ & $\begin{array}{l}\Delta \text { average error } \\
{[\mathrm{K}]}\end{array}$ & $\Delta \sigma[\mathrm{K}]$ \\
\hline$a$ & 15.78 & 8.43 & 2.03 & 2.40 & 2.09 & 1.60 \\
\hline$b$ & 1.71 & 0.72 & 0.01 & 0.12 & 0.21 & 0.19 \\
\hline
\end{tabular}

The absolute differences are shown for variations of $a$ and $b$ between $50 \%$ and $150 \%$ of the original values (see Fig. 9) 


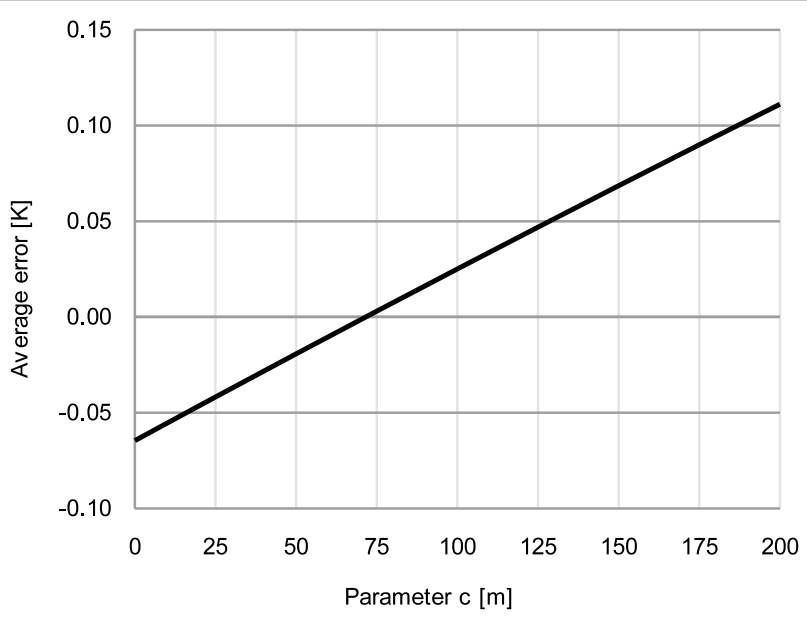

Fig. 10 The average error for method B for a varying parameter c (Eq. 4)

between the surface temperature and the extrapolated log temperature, the larger the disturbance of the temperature profile, i.e. the less the time which has elapsed since the end of mud circulation.

The linear extrapolation is based on the assumption that the thermal conductivity between the surface and the depths from which the extrapolation is carried out does not vary significantly. For the North German Basin and especially the wells used in this study, this assumption is valid as the sedimentary record in general does not show the presence of any major deviations in thermal conductivity between the intervals in question.

Although this general assumption is valid for locations where there are no shallow salt intrusions, the amount of uncertainty introduced by the linear extrapolation was determined. For this, log measurements from greater depths were used to extrapolate the value of the topmost log measurement and the differences were analysed (Fig. 5). The results indicate that the extrapolation leads to a small but systematic overestimation of the topmost log temperature (Fig. 6). The same probably applies to the extrapolation of the surface temperature even though this cannot be verified due to a lack of data.

In systems in which convection dominates the temperature transport even in the topmost few hundred metres, an extrapolation as presented in this study would lead to much larger extrapolation errors. In general, the errors would depend on the position of the well within the convection cell and as such would be hard to quantify. Therefore, extrapolation should be avoided in these cases.

A systematic overestimation of the log surface temperature would lead to an overcorrection of the disturbed temperature logs. However, if method B (Eq. 4) is used for the correction, the maximum error is located at the surface and decreases with depth so that those depths which are of interest either for hydrocarbon or geothermal exploration are less affected. Moreover, the maximum error introduced by the extrapolation is on the order of a few degrees centigrade and therefore comparable to the errors introduced by other potential correction methods (Förster 2001).

If the lithology is taken into account and only data from sediment intervals with a comparable thermal conductivity are considered, the error may even be reduced. For the 
results shown in Fig. 5, log measurements were used without regard to potential lithological variations between the intervals from which the data were taken and those for which the extrapolation was executed.

The rather unexpected observation that extrapolations from greater depths show smaller deviations from the measured value (Fig. 6) can be explained by a feature shown by many temperature logs. This is that the logs exhibit a curvature close to the surface which cannot be explained by changes in thermal conductivity and which is not consistent with the local thermal gradient. This curvature prevents extrapolations starting at $200 \mathrm{~m}$ depth from providing better results than extrapolations starting at $500 \mathrm{~m}$ depth.

\section{Cross-over point}

The determination of the cross-over point in Eq. 3 depends only on the final depth of the well. The underlying assumption here is that drilling progressed with a constant velocity for all analysed wells and that the relationship between the depth of the cross-over point and the final depth of the well will therefore be the same. However, this assumption is not necessarily correct. Equation 1 was derived by Förster (2001) with a regression coefficient of 0.93 for 13 wells which were part of the analysis. Without detailed information about the drilling process in these wells, no better correlation can be established. However, a better correlation could in theory be established for fields where-for several wells-multiple temperature logs were recorded at different times after the end of drilling operations as well as detailed data on the drilling progress with time. In this case, the cross-over point could either be established depending on the final depth of the well or the drilling time.

\section{Equations for correction}

All of the correction methods analysed are based on an accurate knowledge of the crossover point. While method A only rotates the disturbed log around this point, methods B and $\mathrm{C}$ take more information into account.

\section{Method A}

Rotating the temperature log around the cross-over point leads to an overcorrection for temperatures below this point for deeper wells. This becomes apparent in Fig. 11 as the temperature at the final depth of the $\log (4800 \mathrm{~m})$ is increased by more than $11 \mathrm{~K}$ to more than $151{ }^{\circ} \mathrm{C}$, which is higher than the temperature recorded by a production test at nearly the same depth $\left(140^{\circ} \mathrm{C}\right)$.

The problem of overcorrection is also clearly seen in Fig. 8 as the temperature difference between corrected temperatures and measured production test temperatures increases with depth. Method A also exhibits the highest average error and the highest standard deviation of the three methods (Table 1).

\section{Method B}

Method B also rotates the disturbed log around the cross-over point, but also considers the variable duration of the thermal disturbance at different depths by the introduction of an additional term in Eq. 4. That different depths experience different thermal 


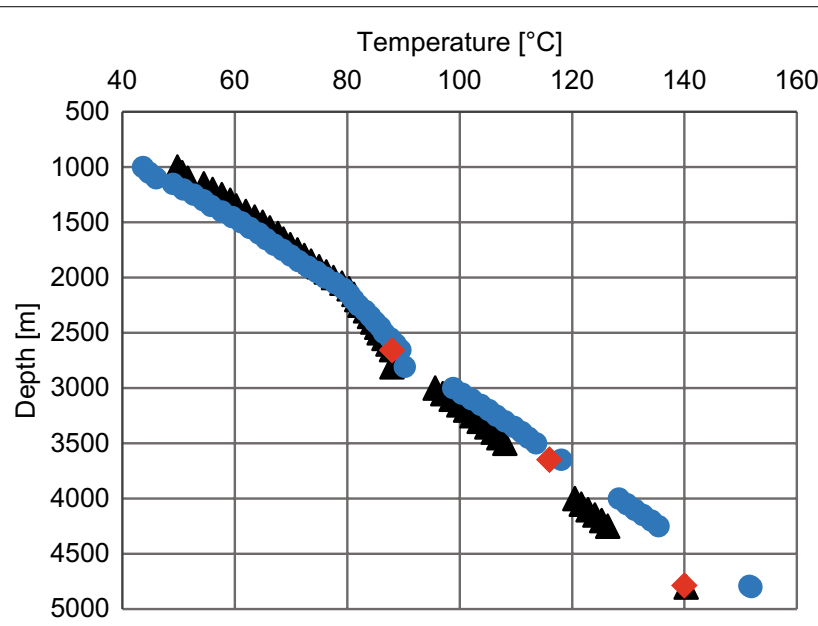

Fig. 11 Overcorrection of temperatures due to log rotation around the cross-over point. Temperature log measurements (black triangles), temperatures recorded during production tests (red diamonds) and log temperature data corrected according to method A (blue dots)

disturbances was shown by Förster (2001), who displayed temperature logs for the well Grevensmühlen 1 which were recorded at different times after the end of mud circulation. Even though the temperature difference between the first and the last measured log is more than $40 \mathrm{~K}$ close to the surface, it is much less at a depth of $5000 \mathrm{~m}$ (only about 20 $\mathrm{K})$. The cross-over point for this well is at about $2200 \mathrm{~m}$.

The reason for this discrepancy is that different parts of the borehole have been subjected to the thermal disturbance by the drilling mud for different periods of time. While the topmost part of the borehole experienced thermal disturbances for the duration of the entire drilling operation, the lowermost part of the borehole was in contact with the drilling mud for a comparatively shorter period of time. Therefore, taking this effect into account as in method B is mandatory for a realistic temperature correction.

However, the underlying assumption leading to the additional term of method $B$ is that drilling progressed with a constant velocity from the surface to the final depth of the well. Of course, in reality this is not the case as the drilling velocity has to be adapted to the lithology. Moreover, technical problems may lead to delays so that the drilling time versus depth relation may not resemble a straight line with a constant slope but rather an irregular curve. If information about large variations in drilling progress is available, it should be incorporated into the correction. In such a case, Eq. 4 can be modified to:

$$
T_{\text {corr }}(z)=T_{\log }-\left(\Delta T-\frac{\Delta T \cdot z}{z_{C P}}\right) \cdot\left(1-\frac{t(z)}{t_{\text {total }}}\right)
$$

where $t(z)$ is the drilling time [d] taken to reach a given depth $z$ and $t_{\text {total }}$ is the total mud circulation time $[\mathrm{d}]$.

Method B shows the smallest average error and standard deviation (Table 1), but it has the tendency to underestimate temperatures which have to be extrapolated from the existing temperature profile downwards. However, for depths covered by the temperature $\log$ profile, method B provides the best correction when compared to production test temperatures. 


\section{Method C}

Method C uses a different approach. For all the analysed wells, Förster (2001) calculated corrected temperatures for the final depth of the profile. The lower part of the disturbed log profile (below the cross-over point) was rotated to match these corrected temperatures. In the upper part of the profile, the same correction as for method A was applied. The quality of this correction method strongly depends on the correct calculation of the lowermost profile temperatures. According to Förster (2001), most of the corrected temperatures have errors of \pm 3 to $5 \mathrm{~K}$. As the lowermost temperatures experience the maximum correction with method $\mathrm{C}$, the errors for temperatures between the cross-over point and the final depth should be lower. However, Fig. 8 shows that a large number of temperatures exhibit an error of more than $5 \mathrm{~K}$. Therefore, the validity of the corrected lowermost profile temperatures given by Förster (2001) has to be questioned. However, due to a lack of independent data, it is not clear if method $\mathrm{C}$ may work well, or at least better, for a different data set. An additional drawback of method $\mathrm{C}$ is the fact that it requires corrected temperatures at the bottom of the temperature profile and therefore cannot be used in areas where this information is lacking.

\section{Sensitivity analysis}

The three correction methods are all based on Eq. 1. The equation contains the empirically derived parameters $a$ and $b$ which themselves have a certain inherent uncertainty. Both parameters were varied in order to test the sensitivity of the results (Fig. 9).

If the parameters are varied within reasonable limits, neither method A nor method $\mathrm{C}$ will approach an average error of zero. It is therefore unlikely that the comparatively large average errors observed for both methods are due to the inherent uncertainty in the empirically derived parameters $a$ and $b$. Rather these differences arise from systematic overestimation of the temperatures arising from the methods themselves.

In different basins, parameters $a$ and $b$ may vary by more than $50 \%$ from the values determined for the North German Basin; they therefore need to be determined for each sedimentary basin independently. However, for each basin both parameters will describe the best-fit comparable to the situation in Fig. 9 of $a^{\prime} / a=1$ and $b^{\prime} / b=1$, respectively. Given a new data set for a new sedimentary basin, the actual errors and standard deviations shown in Fig. 9 may change slightly, but the general trends observable will be repeated. Thus, the conclusions regarding the systematic temperature overestimation of method $\mathrm{A}$ and $\mathrm{C}$ hold true even if the absolute values of parameters $a$ and $b$ may vary significantly in different sedimentary basins compared to the North German Basin.

The sensitivity of method B to variations in parameter $c$ was also tested. Figure 10 shows that the initial assumption of $c=50 \mathrm{~m}$ is close to the optimum value (for the given data set) of $71.6 \mathrm{~m}$. Moreover, the results demonstrate that method B is not very sensitive to variations in $c$ as the average error only varies by $0.2 \mathrm{~K}$ for a reasonable range of values analysed. Variations in $c$ therefore lead to smaller changes in the average error than variations in parameters $a$ or $b$ (Fig. 9). Overall for method B, the choice of a value for parameter $c$ is therefore not critical. However, to achieve the best-fit to the data, parameter $c$ should be optimised for a minimal average error for each new data set individually. 


\section{Application to other locations}

The correction methods presented in this study were developed for wells in the eastern part of the North German Basin. In this area temperature logs of the same well but at different times since the end of mud circulation were available from which to derive an estimate for the cross-over point. Even though no similar data is available for other parts of the basin, it is likely that the correction methods can be applied there without any restrictions or increase in error. This is because the stratigraphy in the western part does not vary significantly from that in the east.

Moreover, Harrison et al. (1982) showed that for a series of wells in Oklahoma, there was little difference between rock temperature and disturbed temperature measurements at depths of between 3,000 and 4,000 ft (about $915 \mathrm{~m}$ to $1220 \mathrm{~m}$ ). Although information about the final depths of the analysed wells was not available, the data indicate that the majority of wells was shallower than $10,000 \mathrm{ft}$ (about $3050 \mathrm{~m}$ ) drilled into mesozoic strata. Assuming that most of these wells targeted either the Spiro or Cromwell Formations, the average depths of bottom formation (average depth + average thickness) is $1624 \mathrm{~m}$ and $1758 \mathrm{~m}$, respectively. Thus, the cross-over points for these wells according to Eq. 1 and using parameters $a$ and $b$ as determined for the North German Basin are 900 $\mathrm{m}$ and $953 \mathrm{~m}$. This is in good agreement with the determination by Harrison et al. (1982) of the depth in which the temperature differences are minimal.

Therefore, it seems likely that Eq. 1, which was developed for the North German Basin is also applicable to other basins. However, in order to provide the best possible temperature correction, parameters $a$ and $b$ of Eq. 1 should be determined for each new field anew-if the necessary information is available-to take possible influences of different lithologies into account.

\section{Comparison to production tests Validity of production test data}

In order to check if the applied corrections lead to temperatures which are closer to the true formation temperatures than before, temperature measurements recorded during production tests were used. For several of the wells investigated, production tests conducted after the temperature log measurements were available. However, not all of the production tests provide reliable temperatures as some of them record temperatures lower than the log temperatures. In these cases, extensive well operations were probably performed before the production test was carried out or the production test may have been preceded by an injection test which could account for the low temperatures. It is therefore not straightforward to identify production tests which can be used to check the quality of the correction methods. Thus, temperature data from production tests (but also other types such as BHT) are always verified by at least two persons before they are incorporated into the Geophysical Information System, which provided the data used for the comparisons.

The production test data available may still contain temperature measurements which do not reflect true formation temperatures but are too low. In this case, the systematic overestimation of temperatures by methods $\mathrm{A}$ and $\mathrm{C}$ would be less pronounced and the results in Table 1 and Figs. 7 and 8 would shift in their favour. However, the great 
majority of the production tests would have to record significantly lower temperatures in order to result in methods $\mathrm{A}$ or $\mathrm{C}$ providing the best results. Given that 84 production test were used, this is highly unlikely. It can therefore be concluded that method B provides the best correction.

\section{Interpolation or extrapolation to production test depth}

The log interpolation and especially the log extrapolation can only be valid if the thermal gradient is constant over the depths over which the interpolation or extrapolation takes place. In cases of log interpolation, this can be ensured as the log data will indicate where changes in the thermal gradient occur. However, log extrapolation is fraught with difficulties as there is no guarantee of a constant geothermal gradient between the depths of the last log measurements and the depth of the production test.

This becomes apparent in Fig. 12, where the extrapolated and interpolated temperatures for a number of production tests in one particular well are compared. The interpolated values were backed by a single log measurement from below the depth of the production tests. For extrapolation, this single measurement was ignored and only measurements to a depth of $3600 \mathrm{~m}$ were used. The extrapolated temperatures are significantly lower than the interpolated temperatures and fail to follow the changing geothermal gradient.

This problem can be avoided if no production test temperatures for which extrapolation is required are taken into consideration. As a minimum requirement for meaningful results, extrapolation should only be employed if there are no significant lithological changes over the extrapolated depth. If this information is not available, the average error with regard to the distance over which the extrapolation occurs can be used to assess the validity of the method.

The average error for the extrapolated log temperatures increases significantly for depth intervals over $1000 \mathrm{~m}$ for the analysed data set (Fig. 13), while up to $1000 \mathrm{~m}$ the

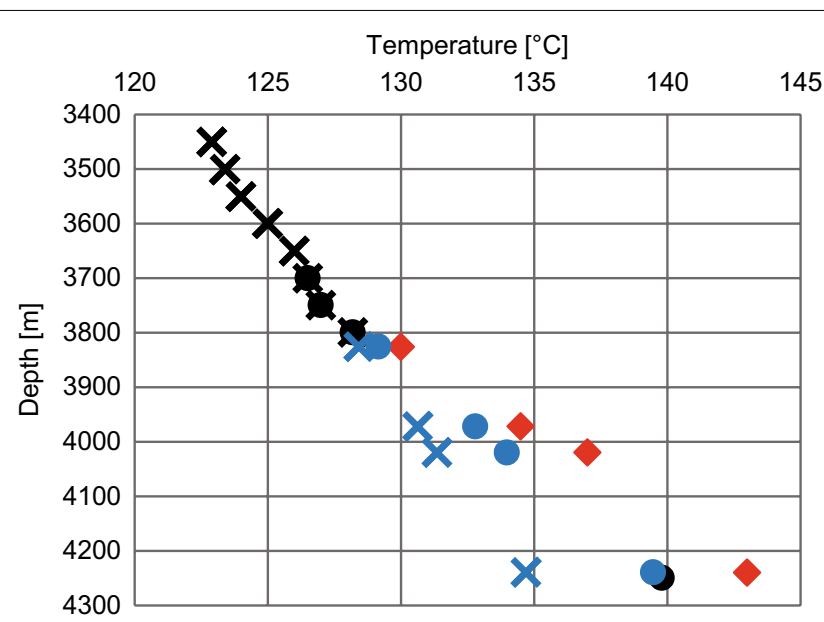

Fig. 12 Comparison of temperature extrapolation and interpolation for one well. Red diamonds: production test temperatures; blue symbols: interpolated (dots) and extrapolated (crosses) production test temperatures; black symbols: log temperatures used for interpolation (dots) and extrapolation (crosses). Some log data were used both for interpolation and extrapolation so that the symbols overlap. No correction is applied 


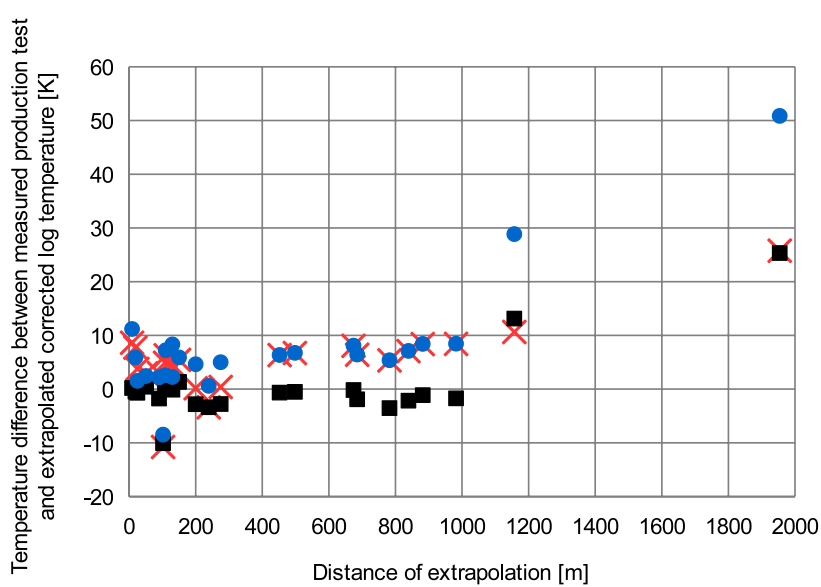

Fig. 13 Temperature difference between production test temperatures and extrapolated log temperatures for the three correction methods. Blue dots: method A; black squares: method B; red crosses: method C

temperature difference between production tests and extrapolated, corrected log temperatures generally lies within a range of $\pm 10 \mathrm{~K}$. Therefore, production test data which are more than $1000 \mathrm{~m}$ deeper than the last log reading were not taken into account to evaluate the quality of the correction methods as the reliability of the comparison is questionable.

However, the average errors for all three correction methods are higher for extrapolated values than for interpolated values (Table 1). This indicates that the assumption that there are only minor changes in lithology is probably not valid for the data used. Nevertheless, method B still provides the best results both for interpolated as well as extrapolated temperatures.

\section{Conclusion}

Of the three temperature methods newly developed for correcting temperature log profiles for wells in the eastern part of the North German Basin, method B shows the best match between the corrected log temperatures and temperatures measured during production tests. Even though the average error for this method is close to zero, the standard deviation of about $3 \mathrm{~K}$ indicates the variability of the data. However, a standard deviation of $3 \mathrm{~K}$ is well within the limits of other correction methods, which rely on much more information prior to the correction.

The advantage of method B compared to previously published correction methods is that in addition to the log values only information about the surface temperature and the final depth of the well are required. The amount of necessary correction does not depend on the time since the end of mud circulation in the well but is approximated by the difference between the true surface temperature and the surface temperature extrapolated from the disturbed log measurements. Therefore, this method introduces the possibility of correcting temperature readings even if vital information about the drilling process is missing and only basic information about the well and the temperatures is known. It therefore offers an opportunity not only to provide more accurate temperature data for 
existing fields, but also to determine whether depleted oil and gas fields are suitable for reuse by geothermal projects, which rely on very accurate thermal data.

Method B as well as the other two methods were developed to correct disturbed temperature profiles from wells in the North German Basin. However, comparison with data from Oklahoma indicates that basic parameters used for the correction are very similar if not the same in other regions of the Earth. Thus, method B offers the possibility to correct disturbed temperature profiles with a minimum in information and is applicable not only to the North German Basin, but also to other sedimentary basins worldwide.

\section{Acknowledgements}

We thank Jörn Brunken for providing the data from the Geophysics Information System FIS-GP (accessible under www.fis-geophysik.de) and Murat Özer for further data compilation. Special thank is addressed to the anonymous reviewers for helpful comments, which improved this article.

\section{Authors' contributions}

SS: conceptualisation, methodology, investigation, formal analysis, writing —original draft, visualisation. IM: writing — original draft (geothermal play type part), writing — review and editing (remaining study). Both authors read and approved the final manuscript.

\section{Funding}

Open Access funding enabled and organized by Projekt DEAL. No funding was received.

\section{Availability of data and materials}

The data that support the findings of this study are available from Bundesverband Erdöl, Erdgas und Geoenergie e.v. (BVEG) but restrictions apply to the availability of these data, which were used under license for the current study, and so are not publicly available. Data are however available from the authors upon reasonable request and with permission of the BVEG.

\section{Competing interests}

The authors declare that they have no competing interests.

\section{Author details}

'Federal Institute for Geosciences and Natural Resources, Stilleweg 2, Hannover 30655, Germany. ${ }^{2}$ Leibniz Institute for Applied Geophysics, Stilleweg 2, Hannover 30655, Germany.

Received: 24 July 2020 Accepted: 15 October 2020

Published online: 09 November 2020

\section{References}

Agemar T, Schellschmidt R, Schulz R. Subsurface temperature distribution in Germany. Geothermics. 2012;44:65-77. https ://doi.org/10.1016/j.geothermics.2012.07.002.

Bayer U, Scheck M, Koehler M. Modeling of the 3D thermal field in the northeast German basin. Geologische Rundschau. 1997:86(2):241-51. https://doi.org/10.1007/s005310050137.

Bonté $D$, van Wees JD, Verweij J. Subsurface temperature of the onshore Netherlands: new temperature dataset and modelling. Netherlands J Geosci Geologie en Mijnbouw. 2012;91(4):491-515. https://doi.org/10.1017/S001677460 0000354.

Bullard EC. The Time Necessary for a Bore Hole to Attain Temperature Equilibrium. Geophysical Supplements to the Monthly Notices of the Royal Astronomical Society. 1947;5(5):127-30. https://doi.org/10.1111/j.1365-246X.1947. tb00348.x.

Cao S, Lerche I, Hermanrud C. Formation temperature estimation by inversion of borehole measurements. Geophysics. 1988:53(7):979-88. https://doi.org/10.1190/1.1442534.

Cherubini Y, Cacace M, Scheck-Wenderoth M, Noack V. Influence of major fault zones on 3-D coupled fluid and heat transport for the Brandenburg region (NE German Basin). Geothermal Energy Sci. 2014;2(1):1-20. https://doi. org/10.5194/gtes-2-1-2014.

Dowdle WL, Cobb WM. Static Formation Temperature From Well Logs - An Empirical Method. J Petroleum Technol. 1975;27:1326-30. https://doi.org/10.2118/5036-PA.

Espinosa-Paredes G, Espinosa-Martínez EG. A feedback-based inverse heat transfer method to estimate unperturbed temperatures in wellbores. Energy Conversion Management. 2009;50(1):140-8. https://doi.org/10.1016/j.encon man.2008.08.017.

Espinosa-Paredes G, Garcia-Gutierrez A. Estimation of static formation temperatures in geothermal wells. Energy Conversion Management. 2003;44(8):1343-55. https://doi.org/10.1016/S0196-8904(02)00117-6.

Feldrappe $\mathrm{H}$, Obst K, Wolfgramm M. Evaluation of sandstone aquifers of the North German Basin: a contribution to the 'Geothermal Information System of Germany'. In: Proceedings European Geothermal Congress, Unterhaching, Germany 2007.

Fertl W, Chilingarian G, Yen T. Determination of true static formation temperature from well logs. Energy Sources. 1986;8(2-3):277-88. https://doi.org/10.1080/00908318608946056. 
Förster A. Analysis of borehole temperature data in the Northeast German Basin: continuous logs versus bottom-hole temperatures. Petroleum Geosci. 2001;7(3):241-54. https://doi.org/10.1144/petgeo.7.3.241 Geological Society of London.

Freymark J, Sippel J, Scheck-Wenderoth M, Bär K, Stiller M, Fritsche JG, Kracht M. The deep thermal field of the Upper Rhine Graben. Tectonophysics. 2017;694:114-29. https://doi.org/10.1016/j.tecto.2016.11.013.

Ganz B. Evaluation of Expert Reports to Quantify the Exploration Risk for Geothermal Projects in Germany. Energy Procedia. 2015;76:341-50. https://doi.org/10.1016/j.egypro.2015.07.839.

Hansen MB, Scheck-Wenderoth M, Hübscher C, Lykke-Andersen H, Dehghani A, Hell B, Gajewski D. Basin evolution of the northern part of the Northeast German Basin - Insights from a 3D structural model. Tectonophysics. 2007;437(1):116. https://doi.org/10.1016/j.tecto.2007.01.010.

Harrison W, Luza K, Prater M, Cheung P, Ruscetta C (1982) Geothermal resource assessment in Oklahoma. Tech. rep., U.S. Department of Energy, Division of Geothermal Energy

Hermanrud C, Cao S, Lerche I. Estimates of virgin rock temperature derived from BHT measurements: Bias and error. Geophysics. 1990;55(7):924-31. https://doi.org/10.1190/1.1442908.

Horner DR. Pressure Build-up in Wells. In: 3rd World Petroleum Congress, World Petroleum Congress, The Hague, the Netherlands, IDWPC-4135, p 191951.

Hoth K, Rusbült J, Zagora K, Beer H, Hartmann O, Schretzenmayr S (eds) Die tiefen Bohrungen im Zentralabschnitt der Mitteleuropäischen Senke: Dokumentation für den Zeitabschnitt 1962 - 1990, Schriftenreihe für Geowissenschaften vol 2. Verl. d. Ges. f. Geowiss., Berlin, 145 pages 1993.

Jaeger JC. The effect of the drilling fluid on temperatures measured in bore holes. J Geophys Res. 1961;66(2):563-9. https ://doi.org/10.1029/JZ066io02p00563.

Jessop AM. Thermal Geophysics. 17: Developments in Solid Earth Geophysics, Elsevier, Amsterdam 1990.

Kühne K, Maul AA, Gorling L. Aufbau eines Fachinformationssystems Geophysik. Zeitschrift für Angewandte Geologie. 2003;2:48-53 (in German).

Kutasov I, Eppelbaum L. A new method for determining the formation temperature from bottom-hole temperature logs. J Petroleum Gas Eng. 2010;1:1-8.

Lachenbruch A, Brewer M. Dissipation of the temperature effect of drilling a well in Arctic Alaska. U.S. Geological Survey Bulletin 1083-C, U.S. Geological Survey 1959.

Majorowicz J, Chan J, Crowell J, Gosnold W, Heaman LM, Kück J, Nieuwenhuis G, Schmitt DR, Unsworth M, Walsh N, Weides $\mathrm{S}$. The first deep heat flow determination in crystalline basement rocks beneath the Western Canadian Sedimentary Basin. Geophys J Int. 2014;197(2):731-47. https://doi.org/10.1093/gji/ggu065.

Moeck I. Catalog of geothermal play types based on geologic controls. Renewable Sustainable Energy Rev. 2014;37:86782. https://doi.org/10.1016/..rser.2014.05.032

Norden B, Förster A, Balling N. Heat flow and lithospheric thermal regime in the Northeast German Basin. Tectonophysics. 2008;460(1):215-29. https://doi.org/10.1016/j.tecto.2008.08.022.

Norden B, Förster A, Behrends K, Krause K, Stecken L, Meyer R. Geological 3-D model of the larger Altensalzwedel area, Germany, for temperature prognosis and reservoir simulation. Environmental Earth Sci. 2012;67(2):511-26. https:// doi.org/10.1007/s12665-012-1709-9.

Perrier J, Raiga-Clemenceau J. Temperature measurements in boreholes. In: Durand B, editor. Thermal phenomena in sedimentary basins: international colloquium, Bordeaux, June 7-10 1983, 41: Collection colloques et séminaires / Institut Français du Pétrole, Éd. Paris: Technip; 1984. p. 47-54.

Przybycin A, Scheck-Wenderoth M, Schneider M. The origin of deep geothermal anomalies in the German Molasse Basin: results from 3D numerical models of coupled fluid flow and heat transport. Geothermal Energy. 2017;5(1):1. https:// doi.org/10.1186/s40517-016-0059-3.

Scheck-Wenderoth M, Cacace M, Maystrenko YP, Cherubini Y, Noack V, Kaiser BO, Sippel J, Björn L. Models of heat transport in the Central European Basin System: Effective mechanisms at different scales. Marine Petroleum Geol. 2014;55:315-31. https://doi.org/10.1016/j.marpetgeo.2014.03.009.

Schulz R, Hänel R, Kockel F. Federal Republic of Germany - West federal states. Geothermal Atlas of Europe. GeographischKartographische Anstalt, Gotha: Hermann Hack Verlagsgesellschaft; 1992. p. 34-7.

Schumacher S, Pierau R, Wirth W. Probability of success studies for geothermal projects in clastic reservoirs: From subsurface data to geological risk analysis. Geothermics. 2020;83:101725. https://doi.org/10.1016/j.geothermic s.2019.101725.

Wang J, Nitschke F, Korzani MG, Kohl T. Temperature log simulations in high-enthalpy boreholes. Geothermal Energy. 2019;7(32) https://doi.org/10.1186/s40517-019-0149-0.

Waples DW, Ramly M. A statistical method for correcting log-derived temperatures. Petroleum Geosci. 2001;7(3):231-40. https://doi.org/10.1144/petgeo.7.3.231.

Yang M, Li X, Deng J, Meng Y, Li G. Prediction of wellbore and formation temperatures during circulation and shut-in stages under kick conditions. Energy. 2015;91:1018-29. https://doi.org/10.1016/j.energy.2015.09.001.

Zare-Reisabadi M, Kamali M, Mohammadnia M, Shabani F. Estimation of true formation temperature from well logs for basin modeling in Persian Gulf. J Petroleum Sci Eng. 2015;125:13-22. https://doi.org/10.1016/j.petrol.2014.11.009.

Zschocke A. Correction of non-equilibrated temperature logs and implications for geothermal investigations. J Geophysics Eng. 2005;2(4):364. https://doi.org/10.1088/1742-2132/2/4/S10.

\section{Publisher's Note}

Springer Nature remains neutral with regard to jurisdictional claims in published maps and institutional affiliations. 